\title{
OPTIMIZATION OF AN ECONOMIC PRODUCTION QUANTITY-BASED SYSTEM WITH RANDOM SCRAP AND ADJUSTABLE PRODUCTION RATE
}

\author{
Yuan-Shyi Peter Chiu ${ }^{1}$ Han-Ying Chen ${ }^{1}$ Singa Wang Chiu' ${ }^{1 *}$ Victoria Chiu ${ }^{2}$ \\ ${ }^{1}$ Chaoyang University of Technology, Taichung City, Taiwan \\ ${ }^{2}$ State University of New York at Oswego, Oswego, New York, United States of America
}

With the aim of increasing capacity to smooth production planning and coping with existence of random scrap in real fabrication processes, this paper explores an economic production quantity (EPQ)-based inventory system with random scrap and adjustable production rate. Mathematical modeling is used to carefully portray and analyze the problem, and the expected system cost function is derived and proved to be a convex function. Then, differential calculus is employed to help determine the optimal batch size for the proposed system. Numerical example along with sensitivity analysis is provided to demonstrate applicability of the obtained results. Analytical outcomes pointed out that this in-depth exploration to the problem reveals diverse important managerial decision-making required information.

Key words: Optimizer, Randomness, Systems, Production planning, Economic production quantity, Adjustable production rate, Inventory system

\section{INTRODUCTION}

This paper explores an economic production quantity (EPQ)-based replenishment system with random scrap and adjustable production rate. Conventional EPQ model [01] assumes perfection in production process and a constant production rate, and it employed mathematical modeling to portray the problem and its relevant parameters, balance setup and inventory holding costs, and determine the most beneficial batch size. In real production environments, owing to diverse unexpected factors, random scrap items produced is inevitable. Mak [02] considered an inventory control problem in which defective items exist and product demand is partial met. Backordering is permitted to satisfy the shortage. The best replenishment theory to the problem was presented and demonstrated by a numerical example. Hariga and Ben-Daya [03] explored an imperfect EPQ problem, in which the production process may shift from in-control status to out-of-control status. For this process transition, they examined effects of both distribution-based and -free bounds on the expected system cost. They also showed the comparison result of optimal solution from their exponential case and the approximate solution from the literature. Jaber [04] studied a lot-size problem considering interruptions for product quality corrections and improvements on reduction of defective rate and consequence quality restoration action. A mathematical model was developed to help analyze the problem, and numerical examples were provided with results discussed. Chakraborty et al. [05] examined an economic manufacturing quantity (EMQ) model with random breakdown, repair, stock threshold level, and variable production rate. They assumed that machine failure is a function of production rate and extra capacity is reserved to cope with possible uncertainties during production process. General failure and repair time distributions were used to build their basic model, and two computational algorithms were proposed to help decide the best production rate and stock threshold level that minimize the expected system cost. Numerical examples were provided to illustrate the key managerial viewpoint insights of their model. Additional studies that addressed diverse aspects of production systems with defective items can also be referred to [06-13].

Moreover, with the aim of increasing machine capacity or reducing production cycle length, expediting production rate can be an effective strategy to achieve these operational goals. de Kok [14] considered a production-inventory control model with a specific (m, M)-policy production rate and a compound Poisson demand process. Approximations to the problem were presented to explore the operating characteristics of the system. As a result, a sequential rule of $(M-m)$ and $m$ was found to be the cost minimization policy subject to a service level constraint. Numerical examples were presented to confirm the accuracy of approximations. Moon et al. [15] examined a single-facility multi-item production system under a rotation production cycle time policy. They assumed that production rates can be reduced from the maximum rate during the production runs. They categorized products by their holding costs and used different production rate to fabricate these different items, with the aim of saving relevant production-inventory cost. Eiamkanchanalai and Banerjee [16] simultaneously determined the optimal runtime and production rate for a single-product fabrication system. They assumed that unit manufacturing cost is a quadratic function of the variable production rate, and explored the effect of variations in production rates on manufacturing cost. 
A numerical example with an iterative solution procedure was provided to show applicability of research result as well as sensitivity analyses. Gharbi et al. [17] studied the problem of production rate control for single-item remanufacturing systems. They considered that in remanufacturing operations for different components repair strategies can be different and executed at different rates, with the objective of defining proper rates to minimize the long-run repair and inventory/shortage costs. A multiple hedging point policy with two thresholds relating to two accelerated repair rates was proposed, to not only determine the parameters of the control policy, but also achieve a close approximation of the optimal repair policy. With the help of design of experiment, simulation modeling, and response surface methodology, they were able to obtain better control policies and demonstrated that the expected cost is lower than what was obtained from using classical hedging point policy. Sicilia et al. [18] investigated the optimal policy for an inventory system with shortage backordering, power demand, and production rate proportional to demand rate. They assumed that during the replenishment period, it is permitted to increase the demand rate, and accordingly, the production rate becomes variable for it is proportional to the demand rate. Stock-out situation is allowed and all shortages are backordered. A solution procedure was proposed to determine the optimal scheduling period, optimal reorder point, and the economic lot size that minimize the total system cost. Numerical examples were provided to demonstrate their model and results. Additional studies related to different aspects of fabrication systems with variable or adjustable production rates can also be found elsewhere [19-27]. In summary, with the aim of addressing aforementioned scrap and capacity increase issues, and providing production managers with a decision support-typed of system to deal with these practical situations, this study develops an exact model to portray the EPQ-based replenishment system with random scrap and adjustable production rate, and explores their effects on the optimal operating decisions. Details on the proposed model are provided as follows.

\section{MATERIALS AND METHODS}

\section{The proposed EPQ-based system}

This section presents the description, formulation, and modeling of the proposed EPQ-based system with random scraps and adjustable fabrication rate. Notations used for the proposed system analysis are given in Table 1 below.

With the aim of shortening production cycle time, the proposed EPQ-based system considers an adjustable production rate $P_{A}$ units per year to meet the annual demand rate $\lambda$ units. The relationship between adjusted production rate and standard (unadjusted) production rate is $P_{A}=\left(1+\alpha_{1}\right) P$, where $\alpha_{1}$ denotes the adjusted proportion and $P$ represents the standard rate. Unit production cost $C_{A}$ and setup cost $K_{A}$ rise accordingly.
The relationships between these costs and the standard ones are as follows: $C_{A}=\left(1+\alpha_{3}\right) C$ and $K_{A}=\left(1+\alpha_{2}\right) K$, where $\alpha_{2}$ and $\alpha_{3}$ denote the increase percentages, and $\mathrm{C}$ and $\mathrm{K}$ are standard unit and setup costs, respectively.

The proposed system also assumes that in production uptime $t_{1 A}$ (Figure 1), an $x$ proportion of defective items is randomly produced at a rate $d_{A}\left(\right.$ so $\left.d_{A}=P_{A} x\right)$, and all defective items will be scrapped in the end of production, at a cost of $C_{s}$ per scrap item. The shortage situations are not permitted in the proposed system, so the following equation must satisfy: $P_{A}-d_{A}-\lambda>0$.

\section{Modeling and analysis}

The maximal quantity of finished products in the end of uptime $t_{1 \mathrm{~A}}$ is

$$
\left.H=\left(P_{\mathrm{A}}-d_{\mathrm{A}}-\lambda\right) t_{1 \mathrm{~A}}=\left(P_{\mathrm{A}}-x P_{\mathrm{A}}-\lambda\right) t_{1 \mathrm{~A}}=\left\{(1-x)\left[\left(1+\alpha_{1}\right) P\right]-\lambda\right\} t_{1 \mathrm{~A}} 1\right)
$$

The maximal quantity of scrap items in the proposed EPQ-based system is $d_{A} t_{1 A}$ or $x Q$ (Figure 2). Upon completion of the production process, depletion of on-hand finished products starts in downtime $t_{2 A}$. The following formulas of cycle time, production uptime, and downtime can be obtained from Figures 1 and 2 .

$$
\begin{aligned}
& T_{\mathrm{A}}=t_{1 \mathrm{~A}}+t_{2 \mathrm{~A}}=\frac{Q(1-x)}{\lambda} \\
& t_{1 \mathrm{~A}}=\frac{Q}{P_{\mathrm{A}}}=\frac{H}{P_{\mathrm{A}}-d_{\mathrm{A}}-\lambda}=\frac{H}{(1-x)\left(1+\alpha_{1}\right) P-\lambda} \\
& t_{2 \mathrm{~A}}=\frac{H}{\lambda}=\frac{\left\{(1-x)\left[\left(1+\alpha_{1}\right) P\right]-\lambda\right\} t_{1 \mathrm{~A}}}{\lambda}
\end{aligned}
$$

Total system cost per cycle of the proposed EPQ system, $\mathrm{TC}(\mathrm{Q})$ consists of production setup cost, variable fabrication and disposal costs, and stock holding costs of finished and defective items in the production cycle, as follows:

$$
\left.T C(Q)=K_{\mathrm{A}}+C_{\mathrm{A}} Q+C_{\mathrm{S}}(x Q)+h\left[\frac{H+d_{\mathrm{A}} t_{1 \mathrm{~A}}}{2}\left(t_{1 \mathrm{~A}}\right)+\frac{H}{2}\left(t_{2 \mathrm{~A}}\right)\right] 5\right)
$$

Substitute $K_{A}, C_{A}, P_{A}$, and $\mathrm{dA}$ in Equation (5), $T C(Q)$ turns into

$$
\begin{aligned}
& T C(Q)=\left[\left(1+\alpha_{2}\right) K\right]+\left[\left(1+\alpha_{3}\right) C\right] Q+C_{\mathrm{S}}(x Q)+ \\
& +h\left\{\frac{H+x\left[\left(1+\alpha_{1}\right) P\right] t_{1 \mathrm{~A}}}{2}\left(t_{1 \mathrm{~A}}\right)+\frac{H}{2}\left(t_{2 \mathrm{~A}}\right)\right\}
\end{aligned}
$$

Further replace $H, t_{1 A}$, and $t_{2 A}$ with the right-hand side results from Equations. (1), (3) and (4) in Equation (6), and apply the expected values of $x$ to cope with its randomness, and with additional derivations, $E[T C U(Q)]$ can be found as follows:

$$
\begin{aligned}
& E[T C U(Q)]=\frac{E[T C(Q)]}{E\left[T_{\mathrm{A}}\right]}=\lambda\left[\left(1+\alpha_{3}\right) C E_{0}+C_{S} E_{1}\right]+\frac{\left[\left(1+\alpha_{2}\right) K\right] \lambda E_{0}}{Q} \\
& +\frac{h Q(1-E[x])}{2}-\frac{h \lambda Q(1-2 E[x]) E_{0}}{2\left(1+\alpha_{1}\right) P}
\end{aligned}
$$

where

$$
E_{0}=\frac{1}{1-E[x]} ; E_{1}=\frac{E[x]}{1-E[x]}
$$


Table 1: List of notations used in the proposed EPQ system

\begin{tabular}{|c|c|}
\hline Symbol & Description \\
\hline$\lambda$ & Product demand rate per unit time in the proposed EPQ system \\
\hline$P_{A}$ & Adjusted production rate of the proposed EPQ system \\
\hline$P$ & Standard production rate in the conventional EPQ system \\
\hline$\alpha_{1}$ & Adjusted proportion of production rate \\
\hline Q & Production batch size of the proposed EPQ system - the decision variable \\
\hline$K_{A}$ & Adjusted production setup cost per cycle in the proposed EPQ system \\
\hline K & Standard setup cost per cycle in the conventional EPQ system \\
\hline$\alpha_{2}$ & Adjusted proportion of setup cost versus the standard setup cost \\
\hline$C_{A}$ & Adjusted unit production cost in the proposed EPQ system \\
\hline C & Standard unit production cost in the conventional EPQ system \\
\hline$\alpha_{3}$ & Adjusted proportion of unit production cost versus the standard one \\
\hline$x$ & Random scrap rate in production process of the proposed EPQ system \\
\hline$d_{A}$ & Production rate of scrap items in the proposed EPQ system \\
\hline$h$ & Unit holding cost per year \\
\hline$C_{s}$ & Unit disposal cost per scrapped item \\
\hline$t_{1 A}$ & Uptime of the proposed EPQ system with adjustable production rate \\
\hline$t_{2 A}$ & Downtime of the proposed EPQ system \\
\hline$T_{A}$ & Cycle time of the proposed EPQ system \\
\hline$E\left[T_{A}\right]$ & The expected cycle time of the proposed EPQ system \\
\hline $\mathrm{TC}(\mathrm{Q})$ & Total system cost per cycle of the proposed EPQ system \\
\hline$E[T C U(Q)]$ & The expected total system cost per unit time in the proposed EPQ system \\
\hline$I(t)$ & On-hand inventory level of perfect quality products at time $t$ \\
\hline$I d(t)$ & On-hand inventory level of scrap items at time $t$ \\
\hline$d$ & Production rate of scrap items in the traditional EPQ system \\
\hline$t_{1}$ & Uptime in the traditional EPQ system \\
\hline$t_{2}$ & Downtime in the traditional EPQ system \\
\hline$T$ & Cycle time in the traditional $E P Q$ system \\
\hline
\end{tabular}

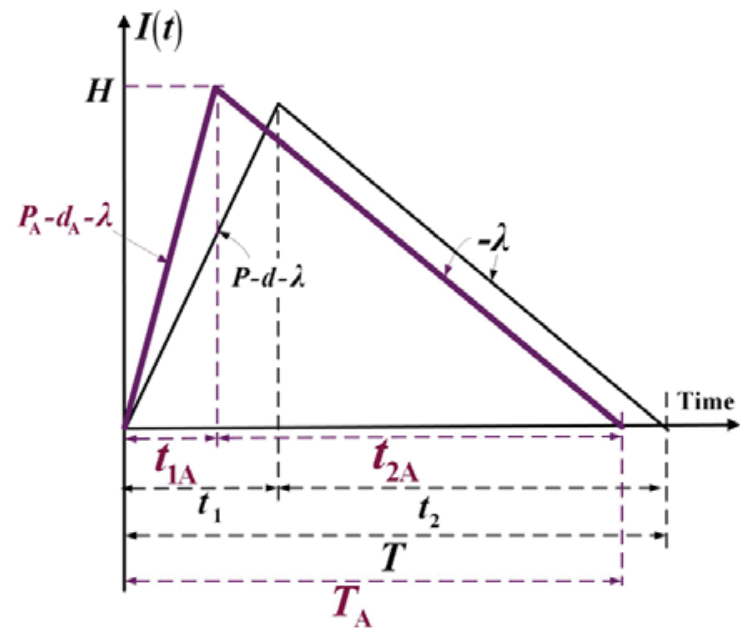

Figure 1: On-hand inventory level of finished products in the proposed EPQ-based system with an adjustable rate (in purple) compared to that in traditional EPQ model (in black)

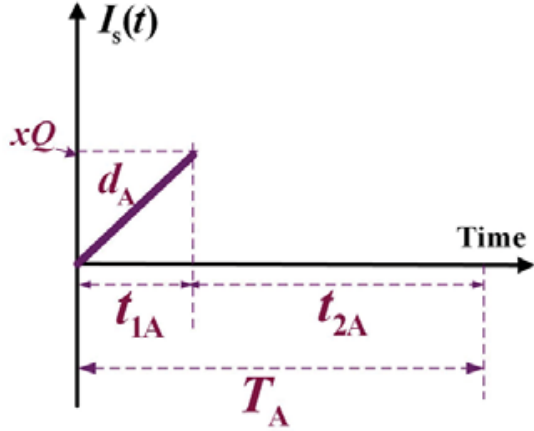

Figure 2: On-hand inventory level of scrap items in the proposed EPQ-based system 


\section{RESULTS AND DISCUSSION}

\section{Determining the optimal replenishment batch size}

First, apply the first and second derivatives of $E[T C U(Q)]$ with respect to $Q$, and we find the following:

$$
\begin{aligned}
& \frac{d E[T C U(Q)]}{d Q}=-\frac{\left[\left(1+\alpha_{2}\right) K\right] \lambda E_{0}}{Q^{2}} . \\
& +\frac{h(1-E[x])}{2}-\frac{h \lambda(1-2 E[x]) E_{0}}{2\left(1+\alpha_{1}\right) P} \\
& \frac{d^{2} E[T C U(Q)]}{d Q^{2}}=\frac{2\left[\left(1+\alpha_{2}\right) K\right] \lambda E_{0}}{Q^{3}}
\end{aligned}
$$

Since Equation (9) results positive (because $\alpha_{2}, K, \lambda, E_{0}$, and $Q$ are all positive), thus $E[T C U(Q)]$ is a convex function for all $Q$ different from zero. To determine the optimal replenishment batch size, one can set Equation (8) equal to zero and solve for $Q^{*}$ as follows:

$$
\begin{aligned}
& \frac{d E[T C U(Q)]}{d Q}=-\frac{\left[\left(1+\alpha_{2}\right) K\right] \lambda E_{0}}{Q^{2}}+ \\
& +\frac{h(1-E[x])}{2}-\frac{h \lambda(1-2 E[x]) E_{0}}{2\left(1+\alpha_{1}\right) P}=0
\end{aligned}
$$

Therefore, $Q^{*}$ can be obtained as follows:

$$
Q^{*}=\sqrt{\frac{2\left(1+\alpha_{2}\right) K \lambda}{h(1-E[x])^{2}-\frac{h \lambda(1-2 E[x])}{\left(1+\alpha_{1}\right) P}}}
$$

\section{Verification of optimal batch size}

Let $\alpha_{1}$ and $\alpha_{2}$ equal to zeros, the proposed system turns into traditional (unadjusted production rate) EPQ model with random scrap, Equation (11) becomes

$$
Q^{*}=\sqrt{\frac{2 K \lambda}{h(1-E[x])^{2}-\frac{h \lambda(1-2 E[x])}{P}}}
$$

Further, if $x=0$, the proposed system becomes a traditional EPQ model [28] as follows:

$$
Q^{*}=\sqrt{\frac{2 K \lambda}{h-\frac{h \lambda}{P}}}=\sqrt{\frac{2 K \lambda}{h\left(1-\frac{\lambda}{P}\right)}}
$$

\section{Numerical example and sensitivity analysis}

This subsection demonstrates the proposed model with the following values of system variables: annual demand rate of a specific product $\lambda=4000$ units; standard production rate $P=20000$ units; assuming adjusted production rate factor $\alpha_{1}=0.5$; hence, $P_{A}=\left(1+\alpha_{1}\right) P=30000$ units per unit time; random scrap rate of production process $x$ (follows a uniform distribution) over the interval of $[0,0.2]$; standard setup cost per cycle $K=\$ 5,000$; adjusted setup cost factor $\alpha_{2}=0.2\left(\alpha_{1}\right)=0.1$; thus, $\mathrm{K}_{\mathrm{A}}=(1$ $\left.+\alpha_{2}\right) K=\$ 5,500$; standard unit production cost $C=\$ 100$; adjusted unit production cost $\alpha_{3}=0.5\left(\alpha_{1}\right)=0.25$; hence, $C_{A}=\left(1+\alpha_{3}\right) C=\$ 125$; unit inventory holding cost per unit time $h=\$ 30$; and unit disposal cost $C_{S}=\$ 20$. Applying Equation (11), we obtain the optimal production batch size $Q^{*}=1444$, and computing Equation (7), we also find the expected total system cost per unit time $E\left[T C U\left(Q^{*}\right)\right]$ $=\$ 598,300$. Variation in batch size $Q$ effects on system cost $E[T C U(Q)]$ is depicted in Figure 3.

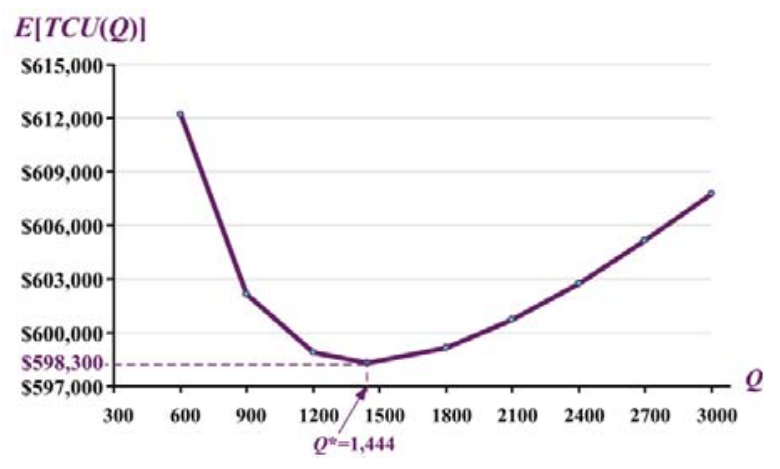

Figure 3: Variation in batch size $Q$ effects on the expected system cost $E[T C U(Q)]$

Variation in random scrap rate effects on various cost components of $E[T C U(Q)]$ is illustrated in Figure 4. It can be seen that as random scrap rate $x$ increases, variable production cost and scrap items' disposal cost go up significantly.

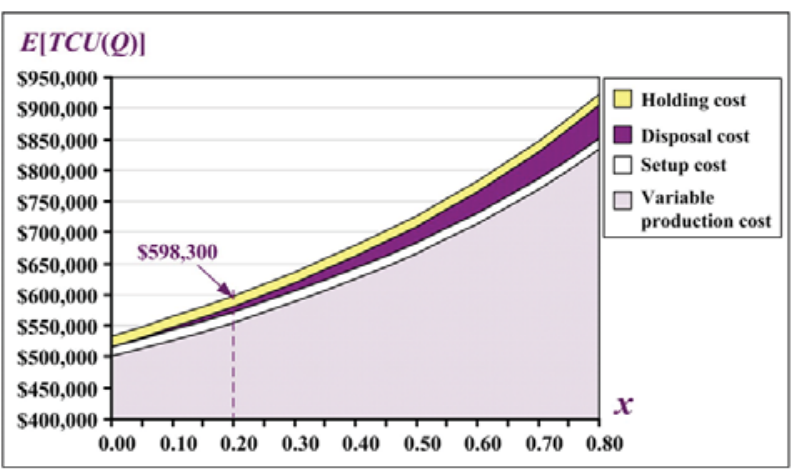

Figure 4: Variation in random scrap rate effects on various cost components of $E[T C U(Q)]$

Joint effects of the batch size $Q$ and random scrap rate $x$ on the expected total system cost $E[T C U(Q)]$ is shown in Figure 5. It is noted that as random scrap rate $x$ increases, the expected total system cost $E[T C U(Q)]$ raises significantly.

Sensitivity analysis on the effect of production rate adjusted ratio $P_{A} / P$ on the percentage of time that machine is used in a cycle (i.e., machine utilization) is depicted in Figure 6. It can be seen that at $P_{A} / P=1.5$ (as assumed in this example), machine utilization decreases from $22.2 \%$ to $14.8 \%$ (i.e., a decrease of $33.33 \%$ ); and as $P_{A} / P$ declines, $t_{1 A} / E\left[T_{A}\right]$ decreases accordingly. Detailed results from the sensitivity analyses are displayed in Table A-1 (see Appendix A). 
Joint effects of random scrap rate $\mathrm{x}$ and production rate adjusted ratio $P_{A} / P$ on the expected total system cost $E[\operatorname{TCU}(Q)]$ is illustrated in Figure 7. It is noted that as random scrap rate $x$ moves up, $E[T C U(Q)]$ raises; and as production rate adjusted ratio $P_{A} / P$ goes higher, expected total system cost $E[T C U(Q)]$ increases, significantly. Further analytical results (as shown in Table A-2) also reveal the effect of production rate adjusted ratio $P_{A} / P$ on the optimal batch size (Figure 8), and the effect of

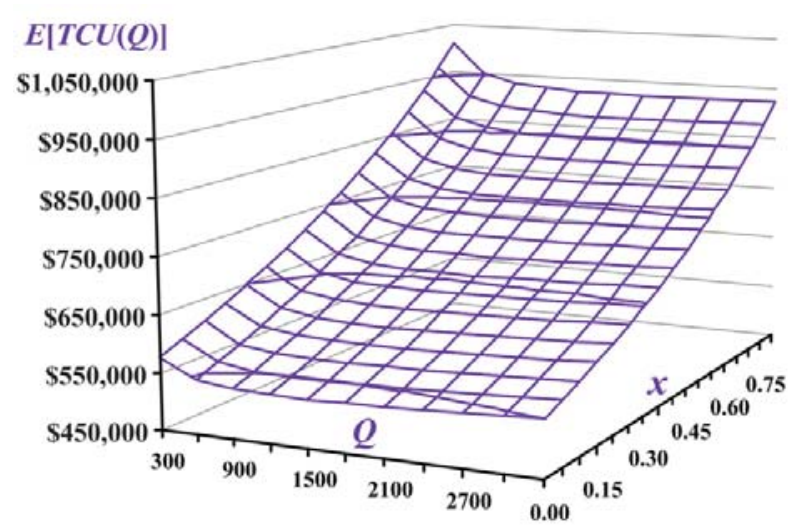

Figure 5: Joint effects of the batch size $Q$ and random scrap rate $x$ on the expected total system cost $E[T C U(Q)]$

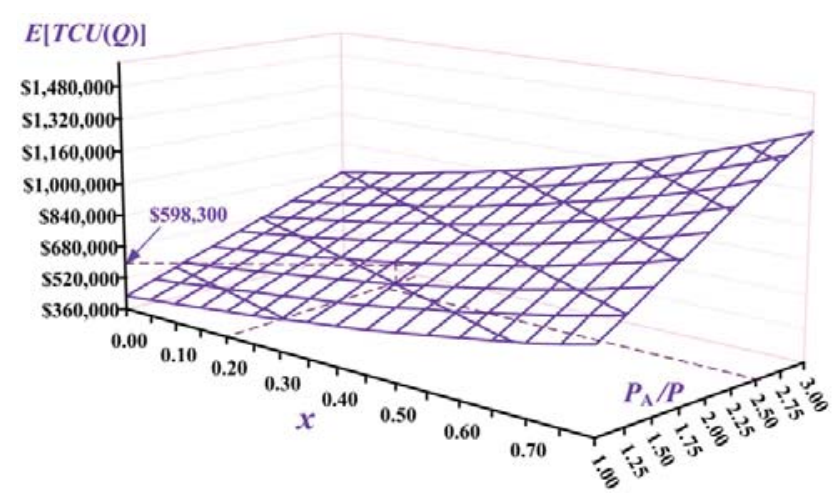

Figure 7: Joint effects of random scrap rate $x$ and production rate adjusted ratio $P_{A} / P$ on the expected total system cost $E[T C U(Q)]$ unit production cost adjusted ratio $C_{A} / C$ on the system's variable production cost (Figure 9).

From Figure 8 , it can be seen that at $P_{A} / P=1.5$ (as assumed in this example), $Q^{*}=1444$; and as $P_{A} / P$ goes up, optimal batch size $Q^{*}$ increases significantly. It is also noted (from Figure 9) that at $C_{A} / C=1.25$ (as assumed in this example), the variable production cost of the system is $\$ 555,556$ (see Table $\mathrm{A}-2$ ), and as $C_{A} / C$ moves up, system's variable production cost increase accordingly.

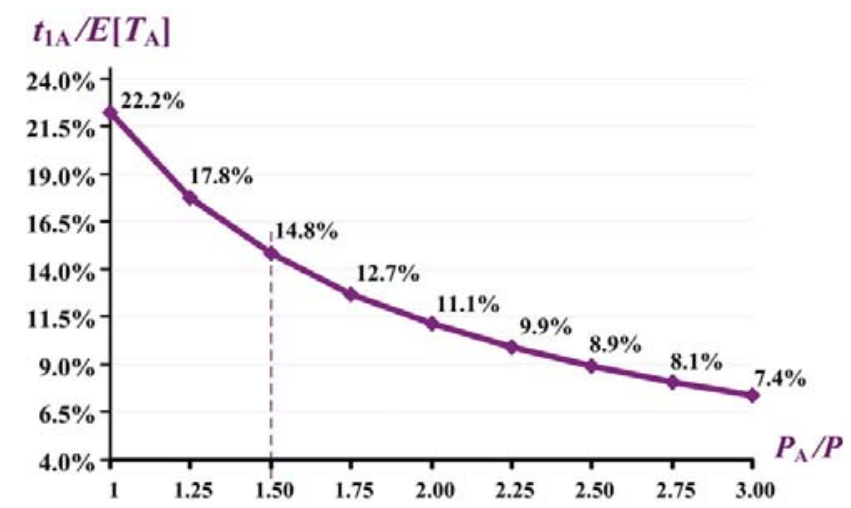

Figure 6: Effect of production rate adjusted ratio $P_{A} / P$ on the percentage of time that machine is used in a cycle $t_{1 A} / E\left[T_{A}\right]$

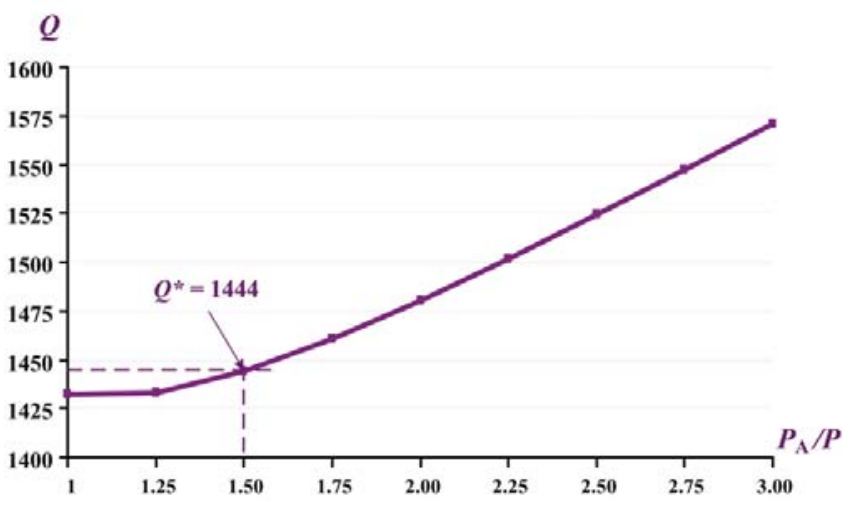

Figure 8: Effect of production rate adjusted ratio $P_{A} / P$ on the optimal batch size

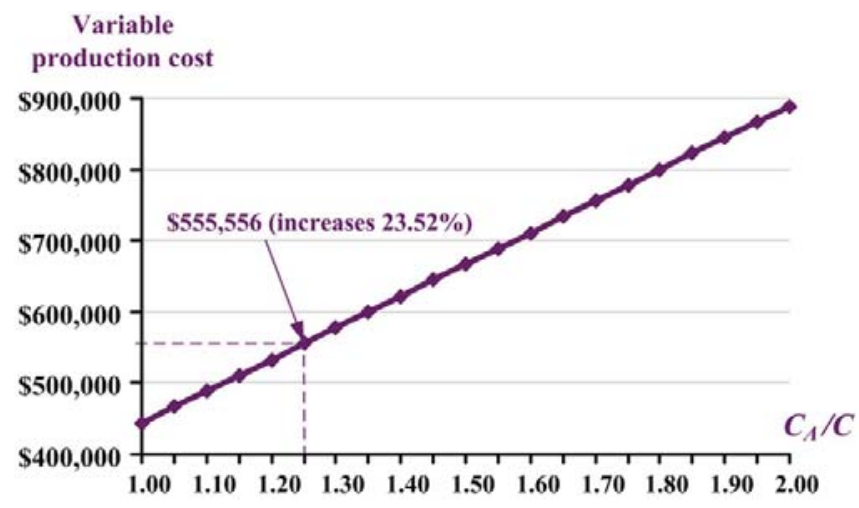

Figure 9: Effect of unit production cost adjusted ratio CA /C on system's variable production cost 


\section{CONCLUSION}

With the aim of increasing capacity to smooth production planning and coping with existence of random scrap in real fabrication processes, this paper examines an economic production quantity (EPQ)-based inventory system with random scrap and adjustable production rate. An exact mathematical model to the problem is built to carefully portray, analyze, and solve the problem. Numerical example along with sensitivity analysis is provided to show the applicability of our obtained results.

Main contributions of this study include (1) for any given adjusted factors on production rate and cost variables, together with other system parameters, the proposed model can help determine the optimal batch size to the problem; (2) for any given random scrap rate of the production process, its effects on optimal batch size and on various system cost components can be obtained; (3) for any given production rate adjusted factor, its effects on machine utilization and optimal batch size can be determined; (4) for any given random scrap rate and production rate adjusted factor, their joint effects on the expected system cost can be revealed; and (5) for any given unit production cost adjusted factor, its effect on system's variable production cost can be obtained. These analytical outcomes indicated that without an in-depth exploration of the problem, many critical managerial decision-making related information (see Figures 3-9 and Tables A-1 to A-2 in Appendix - A) cannot be revealed. Exploring the effect of rework process on optimal batch size and system cost to the problem will be an interesting direction for future study.

\section{ACKNOWLEDGEMENTS}

This study was supported by Ministry of Science and Technology of Taiwan under grant number: MOST-1042410-H-324-008-MY2.

\section{APPENDIX - A}

Table A-1: Production rate adjusted factor effects on production uptime, batch size, the expected cycle time, and machine utilization and its decrease percentage

\begin{tabular}{|c|c|c|c|c|c|}
\hline $\begin{array}{c}1+\alpha_{1} 1 \\
\left(P_{A} / P\right)\end{array}$ & $\begin{array}{l}\text { Production } \\
\text { uptime }\left(t_{1 A}\right)\end{array}$ & $Q^{*}$ & $E\left[T_{A}\right]$ & $\begin{array}{c}\text { Machine } \\
\text { utilization } t_{1 A} / E\left[T_{A}\right]\end{array}$ & $\begin{array}{c}\text { Utilization } \\
\text { decrease \% }\end{array}$ \\
\hline 1.0 & 0.0716 & 1432 & 0.3223 & $22.22 \%$ & - \\
\hline 1.1 & 0.0650 & 1431 & 0.3219 & $20.20 \%$ & $-9.09 \%$ \\
\hline 1.2 & 0.0596 & 1432 & 0.3221 & $18.52 \%$ & $-16.67 \%$ \\
\hline 1.3 & 0.0552 & 1434 & 0.3227 & $17.09 \%$ & $-23.08 \%$ \\
\hline 1.4 & 0.0514 & 1439 & 0.3237 & $15.87 \%$ & $-28.57 \%$ \\
\hline 1.5 & 0.0481 & 1444 & 0.3249 & $14.81 \%$ & $-33.33 \%$ \\
\hline 1.6 & 0.0453 & 1450 & 0.3263 & $13.89 \%$ & $-37.50 \%$ \\
\hline 1.7 & 0.0429 & 1457 & 0.3279 & $13.07 \%$ & $-41.18 \%$ \\
\hline 1.8 & 0.0407 & 1465 & 0.3295 & $12.35 \%$ & $-44.44 \%$ \\
\hline 1.9 & 0.0387 & 1472 & 0.3313 & $11.70 \%$ & $-47.37 \%$ \\
\hline 2.0 & 0.0370 & 1480 & 0.3331 & $11.11 \%$ & $-50.00 \%$ \\
\hline 2.1 & 0.0354 & 1489 & 0.3350 & $10.58 \%$ & $-52.38 \%$ \\
\hline 2.2 & 0.0340 & 1497 & 0.3369 & $10.10 \%$ & $-54.55 \%$ \\
\hline 2.3 & 0.0327 & 1506 & 0.3389 & $9.66 \%$ & $-56.52 \%$ \\
\hline 2.4 & 0.0316 & 1515 & 0.3409 & $9.26 \%$ & $-58.33 \%$ \\
\hline 2.5 & 0.0305 & 1524 & 0.3430 & $8.89 \%$ & $-60.00 \%$ \\
\hline 2.6 & 0.0295 & 1533 & 0.3450 & $8.55 \%$ & $-61.54 \%$ \\
\hline 2.7 & 0.0286 & 1543 & 0.3471 & $8.23 \%$ & $-62.96 \%$ \\
\hline 2.8 & 0.0277 & 1552 & 0.3492 & $7.94 \%$ & $-64.29 \%$ \\
\hline 2.9 & 0.0269 & 1561 & 0.3513 & $7.66 \%$ & $-65.52 \%$ \\
\hline 3.0 & 0.0262 & 1571 & 0.3534 & $7.41 \%$ & $-66.67 \%$ \\
\hline
\end{tabular}


Table A-2:Adjusted ratios of production rate and unit cost effect on optimal batch size, variable production cost, and the expected total system cost and its increase \%

\begin{tabular}{cccccc}
\hline $\begin{array}{c}1+\alpha_{1} 1 \\
(\mathrm{PA} / \mathrm{P})\end{array}$ & $\begin{array}{c}1+\alpha_{3} 3 \\
(\mathrm{CA} / \mathrm{C})\end{array}$ & $\mathrm{Q}^{*}$ & $\begin{array}{c}\text { Variable } \\
\text { Manufacturing cost }\end{array}$ & $\mathrm{E}[\mathrm{TCU}(\mathrm{Q})]$ & $\begin{array}{c}\text { Increase } \\
\%\end{array}$ \\
\hline 1.0 & 1 & 1432 & $\$ 444,444$ & $\$ 484,365$ & \\
1.1 & 1.05 & 1486 & $\$ 466,667$ & $\$ 507,245$ & $4.72 \%$ \\
1.2 & 1.10 & 1472 & $\$ 488,889$ & $\$ 530,067$ & $9.44 \%$ \\
1.3 & 1.15 & 1461 & $\$ 511,111$ & $\$ 552,844$ & $14.14 \%$ \\
1.4 & 1.20 & 1452 & $\$ 533,333$ & $\$ 575,586$ & $18.83 \%$ \\
1.5 & 1.25 & 1444 & $\$ 555,556$ & $\$ 598,300$ & $23.52 \%$ \\
\hline 1.6 & 1.30 & 1437 & $\$ 577,778$ & $\$ 620,990$ & $28.21 \%$ \\
1.7 & 1.35 & 1431 & $\$ 600,000$ & $\$ 643,660$ & $32.89 \%$ \\
1.8 & 1.40 & 1426 & $\$ 622,222$ & $\$ 666,314$ & $37.56 \%$ \\
1.9 & 1.45 & 1422 & $\$ 644,444$ & $\$ 688,953$ & $42.24 \%$ \\
2.0 & 1.50 & 1417 & $\$ 666,667$ & $\$ 711,580$ & $46.91 \%$ \\
\hline 2.1 & 1.55 & 1414 & $\$ 688,889$ & $\$ 734,196$ & $51.58 \%$ \\
2.2 & 1.60 & 1410 & $\$ 711,111$ & $\$ 756,802$ & $56.25 \%$ \\
2.3 & 1.65 & 1407 & $\$ 733,333$ & $\$ 779,399$ & $60.91 \%$ \\
2.4 & 1.70 & 1405 & $\$ 755,556$ & $\$ 801,989$ & $65.58 \%$ \\
2.5 & 1.75 & 1402 & $\$ 777,778$ & $\$ 824,571$ & $70.24 \%$ \\
\hline 2.6 & 1.80 & 1400 & $\$ 800,000$ & $\$ 847,147$ & $74.90 \%$ \\
2.7 & 1.85 & 1398 & $\$ 822,222$ & $\$ 869,716$ & $79.56 \%$ \\
2.8 & 1.90 & 1396 & $\$ 844,444$ & $\$ 892,280$ & $84.22 \%$ \\
2.9 & 1.95 & 1394 & $\$ 866,667$ & $\$ 914,839$ & $88.87 \%$ \\
3.0 & 2.00 & 1392 & $\$ 888,889$ & $\$ 937,393$ & $93.53 \%$ \\
\hline & & & & &
\end{tabular}

\section{REFERENCES}

1. Taft, E.W. (1918) The most economical production lot, Iron Age, 101, pp. 1410-1412.

2. Mak, K.L. (1985) Inventory control of defective products when the demand is partially captive, International Journal of Production Research, 23(3), pp. 533-542.

3. Hariga, M., Ben-Daya, M. (1988) Note: the economic manufacturing lot-sizing problem with imperfect production processes: bounds and optimal solutions, Naval Research Logistics, 45, pp. 423-433.

4. Jaber, M.Y. (2006) Lot sizing for an imperfect production process with quality corrective interruptions and improvements, and reduction in setups, Computers \& Industrial Engineering, 51(4), pp. 781-790.

5. Chakraborty, T., Chauhan, S.S., Giri, B.C. (2013) Joint effect of stock threshold level and production policy on an unreliable production environment, Applied Mathematical Modelling, 37(10-11), pp. 65936608.
6. Kundu, S., Chakrabarti, T. (2015) An integrated multistage supply chain inventory model with imperfect production process, International Journal of Industrial Engineering Computations, 6(4), pp. 565-580.

7. Chiu, Y-S.P., Liang, G-M., Chiu, S.W. (2016) Solving a fabrication lot-size and shipping frequency problem with an outsourcing policy and random scrap, Mathematical and Computational Applications 21(4), art. no. 45.

8. Romero-Jabalquinto, A. Velasco-Téllez, A., Zambrano-Robledo, P., Bermúdez-Reyes, B. (2016) Feasibility of manufacturing combustion chambers for aeronautical use in Mexico, Journal of Applied Research and Technology, 14(3), pp. 167-172.

9. Zhang, D., Zhang, Y., Yu, M. (2016) A machining process oriented modeling approach for reliability optimization of failure-prone manufacturing systems, Journal of Engineering Research, 4(3), pp. 128-143. 
10. Chiu, S.W., Chen, S.W., Chiu, Y-S.P., Li, T-W. (2016) Producer-retailer integrated EMQ system with machine breakdown, rework failures, and a discontinuous inventory issuing policy, SpringerPlus, 5(1), art. no. 339.

11. Zhang, R., Li, J., Wu, S., Meng, D. (2016) Learning to select supplier portfolios for service supply chain. PLoS ONE, 11(5), art. no. e0155672.

12. Chiu, Y-S.P., Chiang, K-W., Chiu, S.W., Song, M-S. (2016) Simultaneous determination of production and shipment decisions for a multi-product inventory system with a rework process, Advances in Production Engineering \& Management 11(2), pp. 141-151.

13. Kaylani, H., Almuhtady, A., Atieh, A.M. (2016) Novel approach to enhance the performance of production systems using lean tools, Jordan Journal of Mechanical and Industrial Engineering, 10(3), pp. 215-229.

14. de Kok, A.G. (1987) Approximations for operating characteristics in a production-inventory model with variable production rate, European Journal of Operational Research, 29(3), pp. 286-297.

15. Moon, I., Gallego, G., Simchi-Levi, D. (1991) Controllable production rates in a family production context, International Journal of Production Research, 29(12), pp. 2459-2470.

16. Eiamkanchanalai, S., Banerjee, A. (1999) Production lot sizing with variable production rate and explicit idle capacity cost, International Journal of Production Economics, 59(1), pp. 251-259.

17. Gharbi, A., Pellerin, R., Sadr, J. (2008) Production rate control for stochastic remanufacturing systems, International Journal of Production Economics, 112(1), pp. 37-47.

18. Sicilia, J., González-De-La-Rosa, M., Febles-Acosta, J., Alcaide-López-De-Pablo, D. (2014) Optimal policy for an inventory system with power demand, backlogged shortages and production rate proportional to demand rate, International Journal of Production Economics, 155, pp. 163-171.

19. Wolisz, A. (1984) Production rate optimization in a two-stage system with finite intermediate storage, European Journal of Operational Research, 18(3), pp. 369-376.
20. Arcelus, F.J., Srinivasan, G. (1987) Inventory policies under various optimizing criteria and variable markup rates, Management Science, 33(6), pp. 756762.

21. Eynan, A. (2003) The benefits of flexible production rates in the economic lot scheduling problem, IIE Transactions, 35(11), pp. 1057-1064.

22. Neidigh, R.O., Harrison, T.P. (2010) Optimising lot sizing and order scheduling with non-linear production rates, International Journal of Production Research, 48(8), pp. 2279-2295.

23. Biel, K., Glock, C.H. (2016) On the use of waste heat in a two-stage production system with controllable production rates, International Journal of Production Economics, 181, pp. 174-190.

24. Sajadi, S.M., Rad, M.F. (2016) Optimal production rate in production planning problem with simulation optimisation approach by simulated annealing, International Journal of Industrial and Systems Engineering, 22(3), pp. 262-280.

25. Dinesh, K.S., Ashwanth, A.R., Karthikeyan, S., Nithyanandam, G.K. (2016) Investigation to improve the new product development process of mono block pump using additive manufacturing. International Journal of Mechanical and Production Engineering Research and Development, 6(2), pp. 77-88.

26. Mičieta, B., Herčko, J., Botka, M., Zrnić, N. (2016) Concept of intelligent logistic for automotive industry. Journal of Applied Engineering Science, 14(2), pp. 233-238.

27. Oblak, L., Kuzman, M.K., Grošelj, P. (2017) A fuzzy logic-based model for analysis and evaluation of services in a Manufacturing company. Journal of Applied Engineering Science, 15(3), pp. 258-271.

28. Nahmias, S. (2009) Production \& Operations Analysis. McGraw-Hill: New York, USA.

Paper submitted: 24.10.2017.

Paper accepted: 21.12.2017.

This is an open access article distributed under the CC BY-NC-ND 4.0 terms and conditions. 